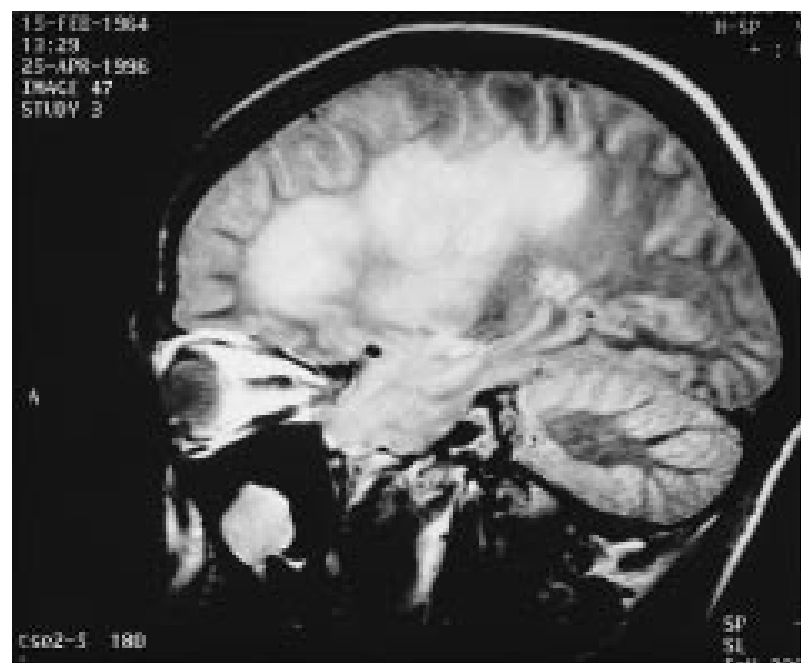

Magnetic resonance head scan (parasagittal view) showing florid high signal white matter changes

remained otherwise well until January, 1996, when he developed recurrent biliary stricturing with jaundice and worsening diarrhoea. Trough cyclosporin concentrations were considered sub-therapeutic at $60 \mathrm{ng} / \mathrm{mL}$ and so he was converted to $\mathrm{N}$ eoral therapy at the same dose. Several 12-h trough whole blood cyclosporin levels were taken over the following 2 months, and did not exceed $125 \mathrm{ng} / \mathrm{mL}$. In $M$ arch, 1996, he complained of altered colour perception, which improved after empirical parenteral vitamin A therapy. In A pril, 1996, he was admitted with coma following recent onset of myalgia and dysarthria. On arrival he was unresponsive, restless, and hyperventilating with decorticate movements, extensor plantar responses, and bilateral ankle clonus. Investigations revealed metabolic acidosis and renal impairment; arterial $\mathrm{pH} 7 \cdot 1$, bicarbonate $8.4 \mathrm{mmol} / \mathrm{L}$, serum creatinine $279 \mu \mathrm{mol} / \mathrm{L}$ (rising from $148 \mu \mathrm{mol} / \mathrm{L} 4$ weeks previously). Serum sodium level was $135 \mathrm{mmol} / \mathrm{L}$. Cyclosporin level was $52 \mathrm{ng} / \mathrm{mL}$. An electroencephalogram and cerebrospinal fluid examination were normal. Computed tomography and magnetic resonance imaging showed white matter changes consistent with leucoencephalopathy (figure), which had progressed substantially since 1993. He was mechanically ventilated and treated with empirical antimicrobial therapy. Cyclosporin and azathioprine were discontinued. $\mathrm{He}$ failed to regain consciousness after withdrawal of sedation and died 20 days after presentation. A screen for viruses taken before death, including PCR analysis of cerebrospinal fluid for JC virus, was negative. Necropsy of the brain revealed axonal degeneration in the areas of white matter abnormality seen on the scans, with associated oedema, scattered lymphocytes, and macrophages localised to the white matter.

This case has clinical, radiological, and pathological features consistent with leucoencephalopathy, a rare condition previously described in patients treated with cyclosporin or tacrolimus. ${ }^{1,3}$ However, most previously described leucoencephalopathies associated with immunosuppression occurred early during therapy and were reversible with good recovery. U nusual features in this case included late onset (3 years after starting immunosuppressive therapy), more extensive and frontoparietal distribution of white matter changes, and deterioration despite withdrawal of cyclosporin, all suggesting an extreme variant of the disease. Neurotoxic side-effects of cyclosporin are more frequently reported in liver transplant recipients than in other organ recipients, which may reflect increased permeability of the blood-brain barrier consequent upon liver failure. ${ }^{1,3,4}$ Other risk factors include high trough cyclosporin concentrations, and low serum cholesterol levels, although a causative effect of the latter is not proven. Neoral, the recently introduced microemulsion formulation of cyclosporin, is more bioavailable than Sandimmun. Patients with liver or gut impairment who are poor absorbers of Sandimmun may be particularly predisposed to increases in peak cyclosporin concentrations when converted to $\mathrm{N}$ eoral. ${ }^{5}$ Our patient had a combination of metabolic derangements that can predispose to encephalopathy, including renal and hepatic impairment and probable bicarbonate deficiency from chronic diarrhoea. Although there was no proof that alteration in his immunosuppressive therapy led to his illness, the increased bioavailability of $\mathrm{N}$ eoral with high peak blood concentrations could have contributed to the development of leucoencephalopathy. Alternatively, this may have been precipitated by worsening metabolic derangement in a predisposed individual. In either case, this report suggests the need for caution when considering alteration of immunosuppressive therapy in patients with intercurrent liver or other metabolic disease, with vigilant observation for neurological side-effects.

We are grateful to Sandoz (UK) L td for helpful discussion.

1 H inchey J, Chaves C, A ppignani B, et al. A reversible posterior leukoencephalopathy syndrome. N Engl J M ed 1996; 334: 494-500.

2 Pullicino $\mathrm{P}$, Zimmer W, K wen PL, et al. Posterior leukoencephalopathy syndrome. Lancet 1996; 347: 1556-57.

3 Boon AP, Adams D H, Carey M P, et al. Cyclosporin-associated cerebral lesions in liver transplantation. L ancet 1988; i: 1457.

4 De Groen PC, A ksamit AJ, Rakela J, K rom RAF. C yclosporinassociated central nervous system neurotoxicity. N Engl J M ed 1988; 318: 789.

5 L evy G A, G rant D, N eoral in liver transplantation. Transpl Proc 1996; 28: $1019-21$.

Liver Unit (N C Fisher) and Departments of Neuropathology, Neurology, and Neuroradiology, Queen Elizabeth Hospital, Birmingham B15 2TH, UK

\section{Multidrug resistance protein in recurrent breast cancer}

Kees Nooter, Guy Brutel de la Riviere, Jan Klijn, Gerrit Stoter, John Foekens

L ack of response to anticancer chemotherapy is one of the main problems in recurrent breast cancer, but the mechanisms underlying this drug resistance are unclear. We studied the expression of multidrug resistance protein $(\mathrm{MRP})^{1}$ in biopsy specimens from 64 primary tumours in patients with operable breast cancer who showed recurrent disease and were treated with chemotherapy as first-line treatment or after showing no response to endocrine therapy. We then related MRP immunoreactivity to patient and tumour characteristics, and treatment outcome. MRP expression was analysed with the M RP-specific monoclonal antibody $\mathrm{MRPr}^{2}$ as described previously. ${ }^{3}$ Staining of tumour cells was scored as negative (weak staining of stromal cells), or positive (weak to strong cytoplasmic and membranous staining).

M RP expression in the primary tumour was positive in eight $(35 \%)$ of the 23 patients who received first-line chemotherapy for recurrent disease and in $12(29 \%)$ of the 41 patients who received chemotherapy after non-response to one or more hormonal treatments. Of the 23 patients receiving first-line chemotherapy, 11 (48\%) responded 
(seven partial or complete responses, four stable disease for more than 6 months), while 12 (52\%) did not. The median time to progression for responding patients was 11 months (range 5-29) and for non-responding patients 3 months (range 0-6). The rate of response did not depend on the type of chemotherapy given. There was no difference between responders and non-responders in age, lymph node status, or recurrence-free period. Two of eight (25\%) postmenopausal patients responded, compared with nine of $15(60 \%)$ premenopausal patients. The incidence of MRP-positive tumours was not different for patients with soft tissue (one of three), bone (two of eight), or visceral metastases (five of twelve) as predominant site of relapse. In patients receiving first-line chemotherapy, MRP was more often positive in non-responding tumours $(50 \%)$ than in responding tumours (18\%). Only one of eight (13\%) M R P-positive tumours had an objective response (5 months), compared with six of 15 (40\%) MRP-negative tumours. Analysing for overall response, including stable disease, two of eight ( $25 \%$ ) M RPpositive tumours responded, compared with nine of 15 (60\%) M RP-negative tumours (odds ratio: $0 \cdot 22 ; 95 \% \mathrm{CI}$ 0.03-1.49). Patients with M RP-positive tumours showed a shorter time to progression on first-line chemotherapy than those with M RP-negative tumours ( $\mathrm{C}$ ox proportional hazard model, $p=0.006$, figure). $T$ he relative hazard rate for time to progression in patients with MRP-positive tumours, compared with M RP-negative tumours, was $4.08(95 \% \mathrm{Cl}$ $1 \cdot 50-11 \cdot 12)$. At 9 months, all eight patients with MRPpositive tumours showed disease progression, while seven of 15 of those with MRP-negative tumours did not (four objective responses, three stable disease). In Cox multivariate analysis for time to progression, M RP was the only significant variable in the model.

Of the 41 patients who received chemotherapy after one or more lines of hormonal therapy, 19 (46\%) responded (seven partial responses, 12 stable disease), whereas 22 $(54 \%)$ did not. In these patients, there was no significant difference in the rate or duration of response, or in the time to progression between patients with MRP-positive and M RP-negative tumours, suggesting differences in tumour cell biology. M etastatic breast cancer patients who receive chemotherapy as the first choice of treatment usually are premenopausal, are oestrogen-receptor and progesteronereceptor negative, and may have visceral metastases. These are all unfavourable prognostic factors. Women first treated with hormonal therapy are usually postmenopausal, have receptor positive tumours, and have bone rather than visceral metastases. We conclude that MRP expression is an

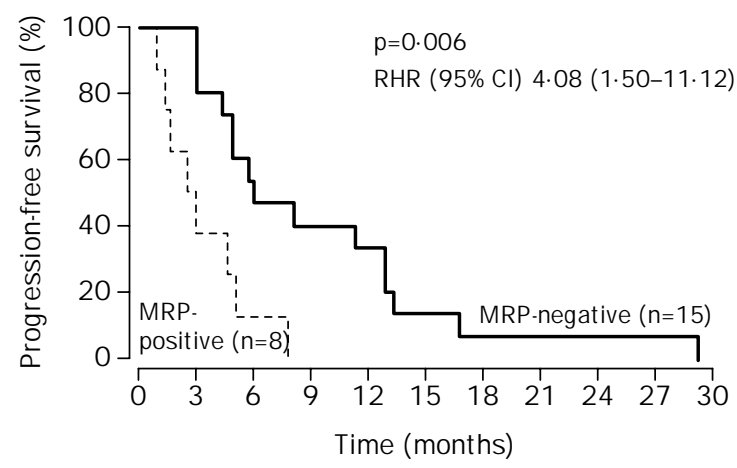

$\begin{array}{llllllllllll}\text { MRP-negative } & 15 & 12 & 7 & 6 & 5 & 2 & 1 & 1 & 1 & 1 & 0\end{array}$ $\begin{array}{llllllllllll}\text { MRP-positive } & 8 & 3 & 1 & 0 & 0 & 0 & 0 & 0 & 0 & 0 & 0\end{array}$

Time to progression for patients treated with first-line chemotherapy for recurrence as a function of MRP status. Patients at risk at start and at every 3 months are indicated RHE=relative hazard rate. important predictor of poor prognosis in patients with breast cancer who were treated with chemotherapy as first-line systemic therapy for recurrence.

We thank $M$ axime $L$ ook for statistical analysis. T his work was supported by the D utch C ancer Society (G rants D D H K 95-1051, D D H K 96-1236).

1 Cole SPC, Bhardwaj G, G erlach JH, et al. O verexpression of a transporter gene in a multidrug-resistant human lung cancer cell line. Science 1992; 258: 1650-54.

2 Flens M J, Zaman GJR, van der Valk P, et al. T issue distribution of the multidrug resistance protein. A m J Pathol 1996; 148: 1237-47.

3 N ooter K, Westerman AM, F lens M J, et al. Expression of the multidrug resistance-associated protein (M RP) gene in human cancers. Clin Cancer Res 1995; 1: 1301-10.

Departments of Medical Oncology (K Nooter) and Clinical Pathology and Division of Endocrine Oncology, University Hospital Rotterdam and Rotterdam Cancer Institute, PO Box 2040, Rotterdam, Netherlands

\section{Complement $\mathrm{C} 3$ and factor $\mathrm{B}$ cerebrospinal fluid concentrations in bacterial and aseptic meningitis}

Philip F Stahel, David Nadal, Hans-Walter Pfister, $P$ Maria Paradisis, Scott $R$ Barnum

Establishing a diagnosis is difficult in most cases of acute meningitis, since its clinical signs are non-specific, and laboratory examination of cerebrospinal fluid (CSF) often does not accurately differentiate between bacterial and aseptic meningitis., ${ }^{1,2}$ Therefore the identification of a discriminating parameter, which might lead to a rapid and accurate clinical test, would be of value in the differential diagnosis of acute meningitis.

Several studies have suggested that the complement system contributes to intrathecal inflammation in bacterial

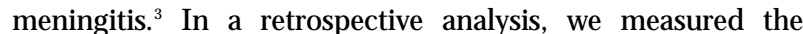
concentrations of the alternative pathway complement components C 3 and factor B in CSF samples obtained by lumbar puncture from 39 patients with clinically suspected acute infectious meningitis, and from 64 controls without central nervous system infection, with an ELISA developed in our laboratory. 18 patients (median age 40 years; range 14-67 years; 9 female) were diagnosed as having bacterial meningitis, on the basis of positive bacterial culture or on detection of bacterial antigen in CSF. The pathogens were Streptococcus pneumoniae $(n=10), H$ aemophilus influenzae (3), $\mathrm{N}$ eisseria meningitidis (3), Listeria monocytogenes (1), and Streptococcus bovis (1). 21 patients were diagnosed as having aseptic meningitis (median age 8 years; range 2 months to 13 years; 6 female) on the basis of CSF pleocytosis with a predominance of mononuclear cells, negative bacterial and fungal CSF and blood cultures, negative results on CSF antigen detection tests for $\mathrm{S}$ pneumoniae, $\mathrm{H}$ influenzae, and $\mathrm{N}$ meningitidis, and full recovery without antibiotic treatment. No patient had received antibiotics or steroids before diagnostic lumbar puncture, and all CSF samples were obtained on admission. The mean $\mathrm{C} 3$ concentration in the CSF of patients with bacterial meningitis (48.32 [SD 50.74] $\mu \mathrm{g} / \mathrm{mL}$ ) was significantly higher than in aseptic meningitis $(2.16[1.82] \mu \mathrm{g} / \mathrm{mL} ; \mathrm{p}<0.001$, Wilcoxon rank sum test) or in controls $(2.49[2.18] \mu \mathrm{g} / \mathrm{mL} ; \mathrm{p}<0.001)$. Similarly, factor $B$ CSF concentrations were significantly raised in patients with bacterial meningitis $(15.89[17 \cdot 36] \mu \mathrm{g} / \mathrm{mL})$ compared with those with aseptic meningitis $(0.25[0.20] \mu \mathrm{g} / \mathrm{mL} ; p<0.001)$ or controls $(0.29[0.26] \mu \mathrm{g} / \mathrm{mL} ; \mathrm{p}<0.001)$. C 3 and factor B CSF concentrations in bacterial meningitis did not correlate 